\title{
Learning Astrobiology 101 with experiments in Baja California, Mexico
}

\author{
Roberto Vázquez ${ }^{1, \star}$ and Patricia G. Núñez ${ }^{2, \star \star}$ \\ ${ }^{1}$ Laboratorio de Astrobiología, Instituto de Astronomía, Universidad Nacional Autónoma de México \\ Km 103 Carretera Tijuana-Ensenada, 22860 Ensenada, B. C., Mexico \\ ${ }^{2}$ Instituto de Estudios Avanzados de Baja California, A. C., Blvd. Tte. Azueta \#147, \\ 22800 Ensenada, B. C., Mexico
}

\begin{abstract}
We present our experience teaching the subject 'Astrobiology 101' ("Introducción a la Astrobiología", in Spanish), given in the University of Baja California at Ensenada, Mexico, since 2004 up to the present. The place of Astrobiology in Mexico, as well as the local academic context in Baja California are presented, as we consider that the multidisciplinary academic environment plays an important role in the motivation of our students. We describe the course itself, its materials, and resources. The course was designed based on classical books as well as news, academic papers, and internet sources. After seven editions of the course, we have noted that making practical experiments improves the understanding of concepts, ideas, and also strengths the interaction among students with different majors. This course has received support by means of an educational grant which objective is to compile all the experimental and hands-on activities in two manuals: one for students and the other for the teachers These manuals will be available to all the Spanish-speaker teachers who want to teach the full course or part of it, as well as those only interested in the hands-on activities. Locally, the establishment of the new Astrobiology Laboratory, in the Institute of Astronomy (UNAM, Campus Ensenada), surely will help us to increase the opportunities on research and education for our students, as well as visiting students and teachers.
\end{abstract}

\section{Introduction}

Teaching an interdisciplinary field, like Astrobiology, can take advantage of many experimental methods, from astronomical observations to growing extremophile organisms in the lab. Since 2004, we have taught the subject Astrobiology 101 ("Introducción a la Astrobiología", in Spanish), as part-time lecturers in the local University (Facultad de Ciencias, Universidad Autónoma de Baja California) in Ensenada (state of Baja California, Mexico). In the following sections we will put in context the influence of the academic environment on the motivation of our students, as well as the rise of Astrobiology in Mexico, outside Mexico City. We also describe the course in detail, including the experimental and hands-on activities we have included. Finally, we will discuss our appreciation about the role of experimentation in such introductory Astrobiology course and what are we doing to improve this aspect in our course.

\footnotetext{
^e-mail: vazquez@astro.unam.mx

$\star \star$ e-mail: pgnunez@ideabc.org
} 


\section{Astrobiology in Mexico}

Historically, Astrobiology in Mexico has been carried out by individuals or small groups. The most known is that of Prof. Rafael Navarro-González (Instituto de Ciencias Nucleares, UNAM), who is the leader of the Laboratory of Plasma Chemistry and Planetary Studies, and participates as part of the team of the Mars Science Laboratory (Curiosity Mission) of NASA. Prof. Navarro has received national and international prizes for his work on Martian analogue soil at the Atacama desert (Chile) and their implications on the limitations of the Viking experiments to find organic matter on Mars surface [1]. Prof. Navarro has served as President of the Mexican Astrobiology Society (SOMA), since 2002 to 2010.

Prof. Antonio Lazcano-Araujo (Facultad de Ciencias, UNAM) is another important researcher in Mexico. His field of study is origin of life. Instead of he is a self-proclaimed non-astrobiologist [2,3], he has served as president of the International Astrobiology Society [4] and also is an enthusiastic participant in Astrobiology conferences around the world [5].

Antígona Segura [6] (Instituto de Ciencias Nucleares, UNAM) and Sandra I. Ramírez [7] (Centro de Investigaciones Químicas, Universidad Autónoma del Estado de Morelos), both former presidents of SOMA (2011-2013 and 2014-2015, respectively), are the new generation of Mexican astrobiologists, doing research on planetary and exoplanetary chemistry, forming new researchers, and actively participating in outreach activities, keeping active their international collaborations. Geoscientists as Guadalupe Cordero, (Instituto de Geofísica, UNAM), Hugo Beraldi and María Colín (Instituto de Geología, UNAM), as well as astrophysicists as Leticia Carigi (Instituto de Astronomía, UNAM), are also members of the Mexican Astrobiology community.

Although all these astrobiologists are based in Mexico City (or very nearby), Astrobiology interest is growing across the country. Currently, active research and education on Astrobiology is present in the states of Nuevo León, Jalisco, Puebla, and Baja California (see section 3).

\section{The Mexican Society of Astrobiology}

The Mexican Society of Astrobiology ("Sociedad Mexicana de Astrobiología", SOMA [8]) is a nonprofit professional organization that groups active researchers, teachers, students, and science popularizers, who are interested in the study and promotion of Astrobiology in Mexico. Founded in 2000 as the Mexican Society for Life Sciences in Space ("Sociedad Mexicana para las Ciencias de la Vida en el Espacio"), quickly their members recognized the importance of Astrobiology and changed the name of the society in 2002. Since then, the members of SOMA have organized ten national conferences, the first seven in Mexico City, and the last three in Cuernavaca (2012), Guadalajara (2014), and Monterrey (2017). In such conferences, researchers and students share their results by means of oral and poster presentations.

SOMA also organizes the Mexican Astrobiology Summer School, held every two years. The cities where the school has been held are: Mexico City (2011), Irapuato (2013), Ensenada (2015), and Hermosillo (2017). In these schools, some introductory and advanced classes are prepared by members of SOMA and local professors, and given to a group of around 30 students selected from all over the country, with almost one-third of students belonging to local institutions.

The Society is a close collaborator of the Mexican Space Agency, an international affiliate partner of the NASA Astrobiology Institute (NAI) [9], and a non-european international partner of the European Astrobiology Network Association (EANA).

SOMA also keeps a strong program of outreach activities across the country. The Asteroid Day, the World Space Week, the national Star Night ("Noche de las Estrellas"), and other local activities 
are great opportunities to promote Astrobiology among the non-academic people in several cities in which there are members of SOMA.

Finally, SOMA has organized the compilation of a textbook, that will help to teach Astrobiology, as well as serve as a reference to researchers and students in Spanish. We hope that this textbook will be published at the beginning of 2018 .

\section{The rich environment at Baja California}

\subsection{Science and technology in Ensenada}

The city of Ensenada, is located in the Northwestern corner of Mexico. With a population of 466,000, it represents $14.88 \%$ of the population of the state of Baja California, in which Tijuana and the capital, Mexicali, have the highest population. The Ensenada population represents $0.4 \%$ of the total of people in Mexico. The city of Ensenada is the capital of the same name municipality, which has, as far as we know, the largest area in the world $\left(51,952.3 \mathrm{~km}^{2} ; 2.6 \%\right.$ of all the Mexican territory [10]).

Instead of its relative small population, Ensenada has a very rich academic environment. The University of Baja California (Universidad Autónoma de Baja California, UABC [11]), is a public institution established in 1957, only a few years after the constitution of Baja California as a state of the republic. Since the beginning, the founders of UABC were aware of the potential of oceanographic studies in the coasts of Baja California. It is well known that the scientists of Scripps Institution of Oceanography, and their work, were an important influence to establish and sustain, in Ensenada, the first marine sciences school in Mexico[12].

In the next decade, the search for a better astronomical site lead the small group of Mexican professional astronomers to move the National Astronomical Observatory from Tonantzintla, Puebla, to San Pedro Mártir, Baja California, inside the municipality of Ensenada [13]. The new observatory gave an important drive to the establishment of a permanent group of astronomers of the National University in Ensenada, as well as other specialized groups in optics, electronics, etc., helping to make a reality a new institution, the Ensenada Center for Scientific Research and Higher Education (Centro de Investigación Científica y Educación Superior de Ensenada, CICESE). This center was originally devised by its first director, Prof. Nicolás Grijalva (a former Professor at Scripps), to be a decentralized center of scientific research and technology development, and was founded in 1973[14].

Currently, Ensenada is considered as the Mexican city with the highest scientist-to-inhabitants ratio [15]. The National University of Mexico (Universidad Nacional Autónoma de México, UNAM), which is the largest university in Latin-America, and one of the top-ranked in the region [16], has two centers at its Ensenada Campus: the Centro de Nanociencias y Nanotecnología and the headquarters of the Observatorio Astronómico Nacional, a branch of the Instituto de Astronomía with main offices in Mexico City. In such centers there is research on Astrophysics, Nanoscience, and related sciences and technology, as well as graduate programs in both disciplines, and even an undergraduate program in Nanosciences [17].

Furthermore, the local campus of the state university (UABC) is formed, among others, by the Institute of Oceanographic Research, the Marine Sciences School, the Sciences School, and the Engineering School. Thus, UABC has research groups as well as undergraduate (and some graduate) programs on: Oceanography, Environmental Sciences, Biotechnology in Aquaculture, Biology, Physics, Mathematics, Computer Sciences, Computer Engineering, Electronics, Bioengineering, and Nanotechnology.

On the other hand, CICESE has grown as the largest federal science center from the Mexican Education Ministry (SEP-CONACYT) [14], with departments in many fields of pure and applied 
sciences: Oceanography Division (Aquaculture, Marine Ecology, Biological Oceanography, Physical Oceanography), Earth Sciences Division (Applied Geophysics, Geology, Seismology), Applied Physics Division (Optics, Electronics and Telecommunications, Computer Sciences), Experimental and Applied Biology Division (Conservation Biology, Marine Biotechnology, Biomedical Innovation, Experimental Microbiology).

A smaller contribution of other public and private universities include: Cybernetics, Renewal Energies, Mechanics, Mechatronics, Software, Electromechanics, Computer Systems, Medicine, among others.

There are other non-profit organizations that promote science, mainly organizing outreach activities, that involve the participation of scientists or science students: 'Caracol' Science Museum and Aquarium, the Youth Scientific Society (Sociedad Cientifica Juvenil, SCJ, having the Mexican representation of the International Association of Physics Students, IAPS[18]), the Baja California Institute of Advanced Studies (Instituto de Estudios Avanzados de Baja California, IdEABC), the association Matematikè, the Ensenada Astronomical Society, etc.

Finally, the location of Ensenada, very close to the San Diego - Los Angeles area, provides to the Mexican academics and students, a unique opportunity to easily visit first level institutions like the University of California campuses, the California Institute of Technology, the NASA Jet Propulsion Laboratory, the Scripps Institute of Oceanography, as well as museums and libraries. In addition, the proximity to high-tech companies makes it possible to buy equipment of very high quality at affordable prices.

\subsection{The contribution of nature}

Baja California also has natural resources that are important to Astrobiology and deserve to be highlighted (see Fig. 1). First of all, the Sierra de San Pedro Mártir, the place where the National Astronomical Observatory is located, has been recognized as one of the three best astronomical sites of the Northern hemisphere, at similar conditions as La Palma (Canary Islands, Spain), and just below Mauna Kea (Hawaii, USA). Clear skies, low humidity, as well as a stable weather, are the main features of this location. Certainly, it was not selected as the alternate site for the Thirty Meter Telescope, but the reasons were not related to its quality [19].

Other astrobiological interest sites in Baja California are related to extreme environments. Two of them are the hypersaline locations of Laguna Figueroa [20] and Guerrero Negro [21], in which microbial mats, formed by extremophile microorganisms, are part of the biodiversity of both locations. Laguna Figueroa is an iconic site, as the young Lynn Margulis collected some samples there. On the other hand, Guerrero Negro is the largest salt mine of the world [22], operating to extract salt since the middles 1950s. Studies about origin of life, as well as viability of terrestrial microorganisms to the extraterrestrial environments, are some of the topics that can be addressed from these hypersaline places.

Finally, towards the South of the peninsula, inside the Gulf of California (called by Jacques Cousteau as the 'Aquarium of the World' [23]), the deepest known high-temperature hydrothermal vents in the Pacific Ocean were discovered: the Pescadero Basin [24]. Hydrothermal vents are very important in studies of origin of life as well as those about the viability of life forms that can live without solar energy, in the deep, and under a high pressure and low temperatures. Such environments are expected to be found under the frozen surface of icy worlds, as Europa or Enceladus [25]. 


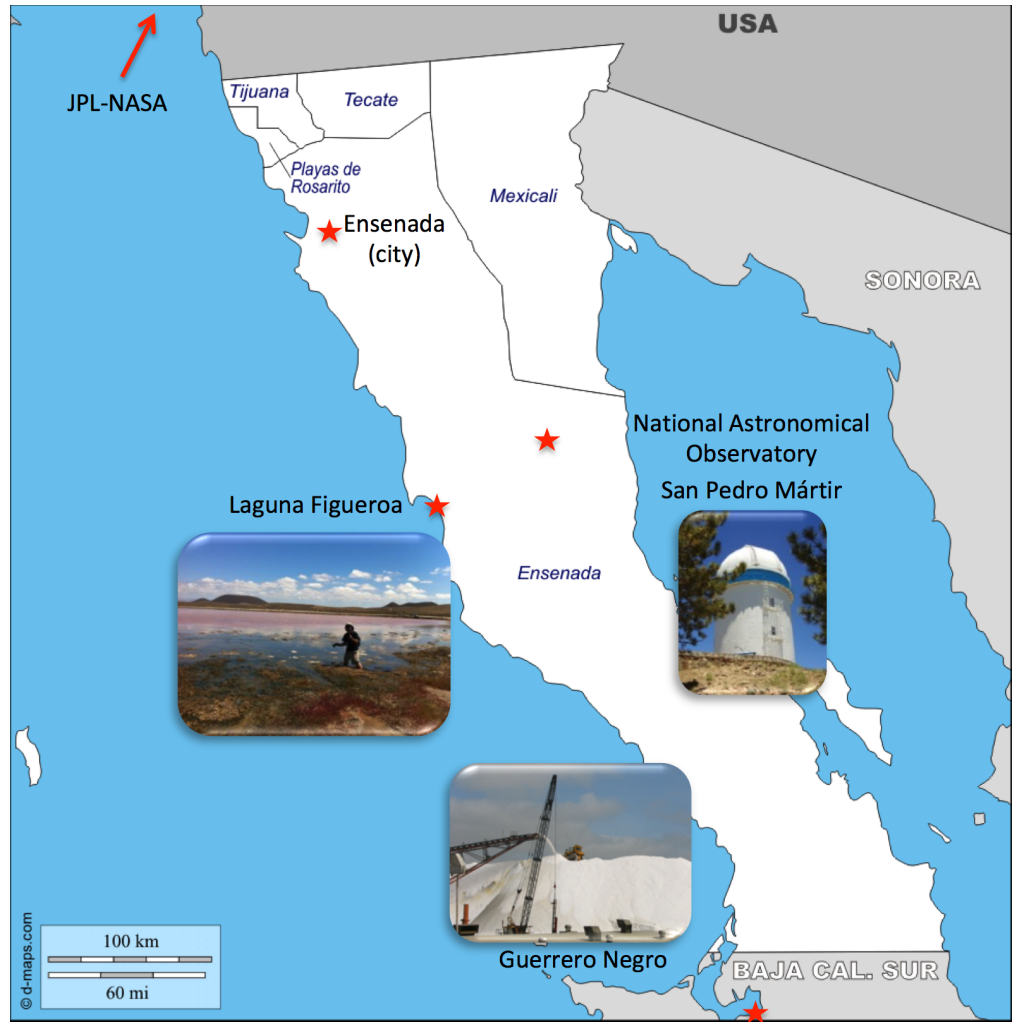

Figure 1. Map of Baja California showing the location of main cities as well as the astrobiological interest sites.

\section{Astrobiology 101}

Under all the academic and natural influence mentioned in Section 4, we designed a course about the fundamentals of Astrobiology based on material from classical books [26-28] as well as news, academic papers, and internet sources. We refer to this course as 'Astrobiology 101' or AB101 (official name Introducción a la Astrobiología), and is part of the Physics curriculum, although it can be taken by students of any major, as an elective subject. AB101 was designed as a 6 hours per week course based on 16 weeks (semester). It is not an advanced course, but an introduction to the main topics in the field. Up to now the course has been taught by two teachers, one biologist and one astronomer.

We plan the course in four blocks, namely:

1. INTRODUCTION: what is Astrobiology?; the strategies of Astrobiology; why are we looking for life outside?

2. THE UNIVERSE: space and time scales; stars and planets formation; stellar evolution; astrochemistry; galaxies; cosmology.

3. LIFE: what is life?; the origin of life; evolution; life on Earth; extremophiles.

4. SEARCH FOR EXTRATERRESTRIAL LIFE: exobiology of the solar system; asteroids, comets, and meteorites; Venus and Mars; icy worlds; exoplanets; SETI; what about UFOs? 
Table 1. A typical class of AB101 is composed by these stages. Hours are always adjustable.

\begin{tabular}{|c|c|c|}
\hline Hour & Block & Description \\
\hline 8:00 am & Presentation & $\begin{array}{l}\text { A classical teacher's presentation (PPTX), trying to have, as much } \\
\text { as we can, questions and opinions from the students. }\end{array}$ \\
\hline 10:00 am & Hands-on & $\begin{array}{l}\text { A practical team activity (team discussions, lab experiments, } \\
\text { computer exercises). This time is granted also to take a break } \\
\text { and take a lunch. The results are discussed in the whole class, } \\
\text { and a written report or pre-report is also presented at the end. }\end{array}$ \\
\hline $12: 30 \mathrm{pm}$ & Video & $\begin{array}{l}\text { In the first editions we watched the series Cosmos, by Carl Sagan. } \\
\text { Now we watch the Neil deGrasse Tyson version, leaving the Sagan } \\
\text { version as a homework to increase the students cultural baggage. } \\
\text { A small discussion is generated after the show. Occasionally we } \\
\text { watch other material in video format, as the series 'The odyssey } \\
\text { of the species ( } L \text { 'Odyssèe de l'espèce, a French documental } \\
\text { about origins of hominids and our own species. }\end{array}$ \\
\hline $2: 00 \mathrm{pm}$ & The end & Final announcements and class dismiss. \\
\hline
\end{tabular}

NOTE: Sometimes, we also change some activity by team presentations of a paper or homework; discussion about the Astrobiology news of the week, etc.

The first time this course was taught (2004) was a great success: we have around 30 students with majors in: Physics, Biology, Math, and Engineering. We found some difficulties trying to organize the schedule during the week, so, for the next editions, we decide to move the class to only on Saturday. The new complication was that the class was too long. At this moment, we have evolved to class as in Table 1.

The course has been a success in all the editions, in which we have taught more than 400 students from many different majors, mostly Biology and Physics. In Table 2 we present the number of students divided by disciplinary major. We can see that, in total, more than $60 \%$ belong to biological sciences, whereas more than $35 \%$ to math, physical sciences, and engineering, and $3 \%$ to other disciplines.

After ten editions of the course, we have learned several things about our students and our course. Certainly, the teacher presentation is important. We try to catch the attention of our students putting the more recent and accurate information in our slides, being visual, asking questions, etc., however, in our own perception, the most effective way that make our students learn new concepts and compare them with their own base knowledge is doing hands-on activities, which include: laboratory experiments, "theoretical experiments", computational experiments, manual calculations, etc., always having intense discussions among the members of the team, and needing only little guidance from the lecturers. These activities not only increase the understanding of concepts and ideas, but also strengthen the interaction among students with different majors, and therefore different visions. Undoubtedly, this interdisciplinary component of the course is one of its most important contributions to the formation of our students, which is difficult to have in other more ordinary courses.

As we (the teachers) integrate the teams, we make sure we have representatives from each discipline in each team. Teams are not formed by 'friends', in many cases the members of a team did not know each other before. Thus, in their practical activities, we note our students learn to work with partners from other majors as a team, pay more attention to their job, and learn to discuss and debate their ideas when they talk with other teams. 
Table 2. Number of students and its disciplinary majors attending AB101.

\begin{tabular}{ccccccccccc}
\hline Edition & Total & BIO & PHY & MTH & CSC & OCN & ESC & BEN & NTC & Others \\
2004 & $\mathbf{2 8}$ & 17 & 8 & 2 & 0 & 1 & 0 & 0 & 0 & 0 \\
2007 & $\mathbf{3 4}$ & 14 & 12 & 5 & 0 & 2 & 0 & 0 & 0 & 1 \\
2009 & $\mathbf{3 2}$ & 25 & 2 & 4 & 1 & 0 & 0 & 0 & 0 & 0 \\
$2009^{*}$ & $\mathbf{4 0}$ & 27 & 4 & 6 & 1 & 0 & 0 & 0 & 0 & 2 \\
$2010^{*}$ & $\mathbf{2 6}$ & 17 & 2 & 3 & 2 & 2 & 0 & 0 & 0 & 0 \\
2010 & $\mathbf{3 6}$ & 14 & 10 & 5 & 3 & 0 & 0 & 0 & 0 & 4 \\
2013 & $\mathbf{4 5}$ & 19 & 9 & 3 & 0 & 5 & 3 & 3 & 3 & 0 \\
2014 & $\mathbf{6 3}$ & 35 & 10 & 1 & 0 & 1 & 0 & 5 & 5 & 6 \\
2016 & $\mathbf{4 7}$ & 25 & 13 & 0 & 0 & 2 & 2 & 3 & 2 & 1 \\
2017 & $\mathbf{6 9}$ & 26 & 32 & 3 & 0 & 7 & 1 & 0 & 0 & 0 \\
\hline Total & $\mathbf{4 2 1}$ & 219 & 102 & 32 & 7 & 20 & 6 & 11 & 10 & 14 \\
\hline
\end{tabular}

${ }^{*}$ Given in intersemestral term (intensive course: 96 hours in 4 weeks).

NOTE: Disciplinary majors are: BIO (Biology), PHY (Physics), MTH (Mathematics), CSC (Computer Sciences), OCN (Oceanography), ESC (Environmental Sciences), BEN (Bioengineering), NTC (Nanotechnology), and Others (includes students from Medicine, Genomics, Electronics, Architecture, Gastronomy [yes, is not a joke], one Ecology graduate student, one Elementary School teacher, and three High-School [very self-motivated] students).

\section{The hands-on activities}

Almost two years ago, we received financial support from UNAM by means of the DGAPA-PAPIME grant PE109915. The aims of the project is to compile different activities and experiments and write manuals to be used in our course, but also in courses given by other Spanish-speakers teachers and their students, in Mexico or abroad. These manuals (student and teacher versions) could also be used in summer schools, science boot camps, and outreach activities, because they would be of different grades of skills. Thus, we were able to buy equipment to be used in our practices (lab equipment, a telescope, computers, etc.), as well as some materials, experimental kits, etc.

We have designed our own exercises, by example, the Models on the ground, in which students will be sensitive to the Solar System scale, by walking across the campus, finding the distance from the basketball ball size Sun, to all the planets. Other exercise from our own is finding exoplanets using a old eclipse model and a photodetector circuit. We also have planned observations and photography (using smartphones) to estimate the size of Moon mountains, the period of Galilean satellites (and then estimate the mass of Jupiter), etc. Also use of public astronomical databases will be included. About lab experiments we have some observations (and also photographs), to measure sizes and analyze forms and structures of: tardigrades (water bears), pollen grains, and Artemia salina (Sea-Monkeys).

External activities from the experimental kits of Carolina Biological Supply Company are also included. They are kits for extreme life, DNA extraction, evolution game, etc. We have translated to Spanish some of the manuals of Carolina(C) kits with permission, and hope we can integrate their exercises in our manuals.

Astronomical experiments of the Project CLEA [29], are also very useful when telescopes are not available (or even using them together). We have been granted permission to translate those manuals to Spanish and also we will integrate such exercises to our manuals.

Finally, the astrobiological NASA-CERES-MSU exercises are another source of interesting hands-on activities like the trip to Mars or the designing your creature. We have received a posi- 
tive answer to our ask for translation plus integration to our manuals. Formal permissions are not granted, but we are confident that they can be obtained.

\section{Final comments}

According to our experience with hands-on activities, from theoretical experiments to formal lab practices, we find these are a powerful tool to be used in the learning-teaching process of Astrobiology. We have described how and why we design the course Astrobiology 101 inside a rich academic environment, and how the practical activities, designed to solve a schedule problem, have become in a key piece to this introductory course.

We hope that, in a few months, the manuals can be available through the institutional website of the Laboratory (www.astrosen.unam.mx), and we will start to receive feedback from other teachers and students.

We also will keep improving and increasing the number of experiments and other hands-on activities to have more choices when someone wants to teach a concept, principle or idea.

We thank the academic authorities of Facultad de Ciencias (UABC) and Instituto de Astronomía (UNAM) for their continuous support to the course AB101. We also thank to SOMA members, as well as ISE2A attenders and organizers, for the useful discussions about teaching Astrobiology, and for giving us the opportunity to share our experiences. We also thank to our referee, Prof. Susana Deustua, for her useful comments that significantly improved this work. We are grateful to Lucy Jaen and Fernanda López for their support in translation of printed material of some practical activities from English to Spanish. Finally, we also thank the support of grants UNAMDGAPA-PAPIME PE109915 and CONACYT-AEM 275311.

\section{References}

[1] Navarro-González, R., Navarro, K. F., De la Rosa, J., Iñiguez, E., Molina, P., Miranda, L. D., Morales, P., Cienfuegos, E., Coll, P., Raulin, F., Amils, R., McKay, C. P. PNAS, 103, 16089-16094 (2006)

[2] Lazcano, A., Hand, K.P. Nature, 488, 160-161 (2012)

[3] Lazcano, A. (2017, September 27). Retrieved from https://www.youtube.com/watch?v=uO7DRoBgu3I

[4] ISSOL, (2017, September 27). Retrieved from http://issol.org/about/history/

[5] IAU, (2017, September 27). Retrieved from http://astrobiology2017.org/speakers/

[6] Segura, A., Walkowicz, L. M., Meadows, V., Kasting, J., Hawley, S. Astrobiology, 10, 751-771 (2010)

[7] Ramírez, S. I., Navarro-González, R. Coll, P., Raulin, F. Advances in Space Research, 36, 274$280(2005)$

[8] SOMA, (2017, September 28). Retrieved from http://www.soma.org.mx

[9] NAI, (2017, September 27). Retrieved from https://nai.nasa.gov/international-partners/

[10] Gobierno de Baja California, (2017, September 28). Retrieved from http://www.bajacalifornia.gob.mx/portal/nuestro_estado/municipios/ensenada/extension.jsp

[11] Piñera, D. (coord)., Historia de la Universidad Autónoma de Baja California 1957-1997, (UABC, Mexicali, 1997) 632p; ISBN 968-7326-63-8

[12] Shor, E. N., Scripps Institution of Oceanography: probing the oceans 1936 to 1976, (Tofua Press, San Diego, 1978) 502p; ISBN 0-914488-17-1

[13] Tapia, M., Cruz-González, I., Ávila, R. Revista Mexicana de Astronomía y Astrofísica, 28, 9-15 (2007) 
[14] CICESE, CICESE, los primeros 40 años, (CICESE, Ensenada, 2013) 233p. Available online www.cicese.edu.mx

[15] Díaz de León, J. N., Zavala-Sánchez, L. A. Mundo Nano, 10, 69-84 (2017)

[16] Minsky, C. (2016, July 7). Retrieved from https://www.timeshighereducation.com/student/news/top50-universities-latin-america-revealed

[17] Pino-Farías, M. A. J. (ed.), La ciencia en la UNAM 2015 a través del Subsistema de la Investigación Científica. (UNAM, Mexico City, 2015) 248p; ISBN 978-607-02-7343-8

[18] IAPS, (2017, September 28) Retrieved from http://www.iaps.info/members/list-of-iapsmembers/national-committees/nc-mexico

[19] TMT, TMT alternate site: Observatorio de Roque de los Muchachos, (TMT, December 2016) 10p. Available online www.tmt.org

[20] Margulis, L., Barghoorn, E. S., Ashendorf, D., Banerjee, S., Chase, D., Francis, S., Giovannoni, S., Stolz, J. Precambrian Research, 11, 93-123 (1980)

[21] Valdivieso-Ojeda, J. A., Huerta-Diaz, M. A., Delgadillo-Hinojosa, F. Chemical Geology, 363, 341-354 (2014)

[22] ESSA, (2016, August 16). Retrieved from http://www.essa.com.mx/acerca_de_essa.aspx

[23] Kelsey, E. Watching giants: the secret lives of whales. (University of California Press, Berkeley/Los Angeles/London, 2009) ISBN 978-0-520-26158-7

[24] Goffredi, S. K., Johnson, S., Tunnicliffe, V., Caress, D., Clague, D., Escobar, E., Lundsten, L., Paduan, J. B., Rouse, G., Salcedo, D. L., Soto, L. A., Spelz-Madero, R., Zierenberg, R., Vrijenhoek, R. Proceedings of the Royal Society B, 284, 20170817, DOI: 10.1098/rspb.2017.0817

[25] Vance, S., Harnmeijer, J., Kimura, J., Hussmann, H., deMartin, B., Brown, J. M. Astrobiology, 7, 987-1005 (2007)

[26] Goldsmith, D., Owen, T. The Search for Life in the Universe, (University Science Books, 2001) 573p; ISBN 1-891-38916-5

[27] Gilmour, I., Sephton, M. A. An Introduction to Astrobiology, (Cambridge University Press, Cambridge, 2004) 358p; ISBN 0-521-83736-7

[28] Chela-Flores, J. The New Science of Astrobiology, (Springer, Netherlands, 2001) 253p; ISBN 978-0-7923-7125-0

[29] Marschall, L. A., Snyder, G. A., Cooper, P. R. The Physics Teacher, 38, 536 (2000)

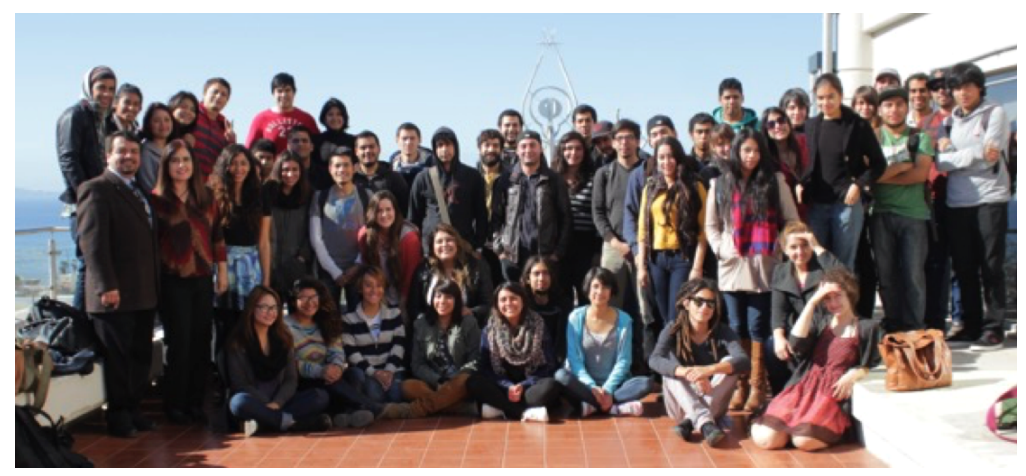

Figure 2. Astrobiology 101 at Ensenada, Class 2014. 